\title{
A Study of Informal Learning Communities: a Tale of Two Physics Courses
}

\author{
Yuehai Yang*, Binod Nainabasti ${ }^{\dagger}$, David T. Brookes ${ }^{\dagger}$, and Eric Brewe ${ }^{\dagger}$ \\ * Department of Physics, California State University, Chico, Chico, CA 95929 \\ ${ }^{\dagger}$ Department of Physics, Florida International University, Miami, FL 33199
}

\begin{abstract}
We asked students in two second-semester introductory college physics courses to report on a weekly basis who they worked with on physics outside of class time. One course was a lecture-based course while the second was a studio-based student-centered course implementing the Investigative Science Learning Environment (ISLE). We used social network analysis to visualize and quantify each student's position and engagement in the informal learning community that formed outside of class. Our study analyzed the relationship between students' network positions as they worked together in groups outside the classroom with their performance in the course. We interpreted our results through a participationist viewpoint on learning. Comparisons between the two courses revealed interesting similarities and differences. While the learning communities in these two distinct settings may look very different, our results showed the overarching importance of informal learning communities irrespective of course type.
\end{abstract}

Keywords: Participation, Informal Learning community, Social Network Analysis, PageRank Centrality PACS: 01.40.Fk, 01.40.Ha

\section{INTRODUCTION}

The importance of student interactions and participation in a learning community are established as the foundation of sociocultural learning theory [1]. Social network analysis (SNA) can improve our understanding of student network formation in and outside of classrooms, quantify their participation in the learning community, and explore the impacts of these networks on student learning. Different types of network analysis in the learning of physics are emerging [2-6]. SNA has been widely used in the field of education to investigate leadership at schools [7-9], the relationship between social networks and educational change [10], and how students' online interactions related to their academic performance [11-13]. In the context of a university physics course, we can use self-reported student connections outside of the classroom to discuss how centrality measures, which quantitatively describe each student's position and relative importance in a network, can be related to class settings, student interactions and student performance. We do not intend to say that students who have a more central role in this informal network will learn physics better, but instead we apply this analysis to empirical data sets of self-reported student connections from two classes and argue that identifying the patterns of collaboration and interactions provide a meaningful way to understand mechanisms for improving student performance and success in physics classes.

\section{METHODOLOGY}

The network analysis data were collected from two second-semester introductory physics classes at California State University, Chico (CSUC) and Florida International University (FIU), both of which were composed of students from multiple majors. The CSUC class was a traditional lecture-based course, which included separate lecture and laboratory settings. The FIU class was an integrated physics course with white board problem solving, labs, and review sessions, implementing the Investigative Science Learning Environment (ISLE) [14]. During class periods at FIU, students worked collaboratively, shared ideas and tried to convince each other about their own ideas and understandings. This approach resembles the processes that scientists follow to acquire new knowledge.

In a weekly self-reported survey, students enrolled in the second semester introductory physics courses from both classes indicated with whom they remembered having studied physics outside of the class time. The weekly reported connections were recorded into an $\mathrm{N} \times \mathrm{N}$ adjacency matrix, where $\mathrm{N}$ is the number of students in each class, to create a 
network of connections describing the informal learning community for each week. A no-response survey was treated the same as a zero-connection report for that week. With the accumulated data of the matrices from all weeks, we calculated PageRank centralities [15] for all students and examined the correlation between these measures and course grades from the introductory physics class.

\section{SOCIOGRAMS}

To visualize the informal learning communities formed outside of the two classrooms, sociograms of both classes over the whole semester were made by using Gephi and shown in Figures $1 \mathrm{~A}$ and B. The general patterns of these two sociograms showed consistency with the findings from our previous study of the formal learning environments at FIU [16]. For each node in the networks, the directed and weighted PageRank centrality was calculated using matrices made from students' weekly reported data over the whole semester. The size of the node indicates the PageRank of the student, and the color (grayness) denotes the in-degree [15] of a student, which is the number of classmates who reported her/him as one of their study partners outside of the classroom. The thickness of an edge shows the weighted strength (the number of reports for the same connection) [15] of the tie between the two connected students.

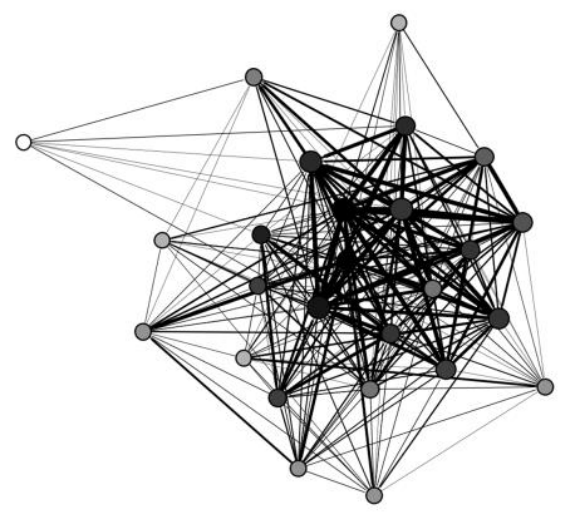

FIGURE 1A. Whole semester sociogram of informal learning community in the ISLE class.

The sociogram of the ISLE class (Figure 1A) reveals that all students were integrated into the network over the course of the semester. The smallest number of ties (in-and out-degree) for an individual student is 7 , while the greatest is the maximum possible number: 25 (26 students in total). In clear contrast, the sociogram of the lecture class (Figure 1B) shows that most students were isolated in several small subgroups, of which each was formed mainly by students of the same major. For example, subgroup 1 was formed mainly by students from the construction management program and subgroup 2 by biological science majors. Meanwhile, 31 students among the total 72 in the lecture class remained unconnected. For those who were connected with other classmates, the greatest number of accumulated ties for an individual student is only 6 .

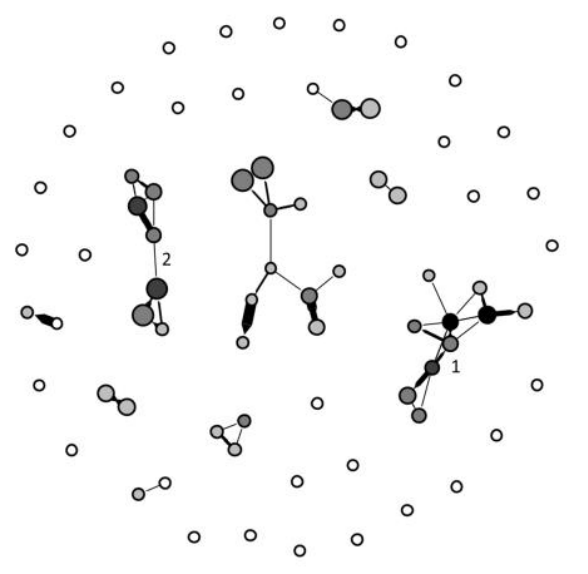

FIGURE 1B. Whole semester sociogram of informal learning community in the lecture class.

\section{DEGREE DISTRIBUTION}

Degree distribution provided another perspective to analyze students learning community networks of both ISLE and lecture classes. Figures 2A and B show differences between these two classes in their propensity to accumulate student connections over the semester. We calculated the in-degree distribution of both classes using the first weekly reported data collected at the beginning of the semester and the accumulated data of the whole semester. The value of the in-degree of one student in the degree distribution plot is the number of edges in the sociogram directed towards the student actor. In-degree is also an essential factor in PageRank centrality calculations.

The degree distribution of ISLE class data indicates that at the beginning of the semester, out of 26 enrolled students, $19(73.1 \%)$ were reported working with 2 or fewer classmates. After the semester, this number dropped to 1 (3.8\%), and 12 (46.2\%) students were reported by 19 or more of their classmates. In the contrast, students from the lecture class did not accumulate reported connections with a diversity of classmates like students from the ISLE class did. At the beginning of the semester, out 
of 72 enrolled students in the lecture class, 64 (88.9\%) were reported working with 1 or fewer classmates. By the end of the semester, this number dropped to $53(73.6 \%)$. The greatest number of reported cumulative connections (in-degree) was only 4.

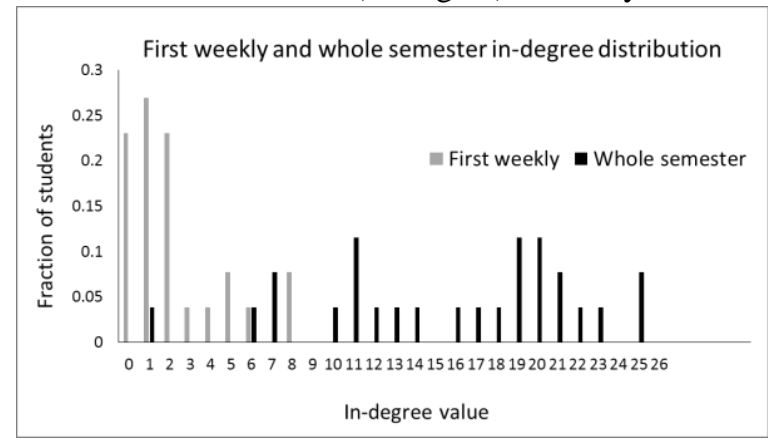

FIGURE 2A. First weekly and whole semester in-degree distribution of informal learning community in the ISLE class.

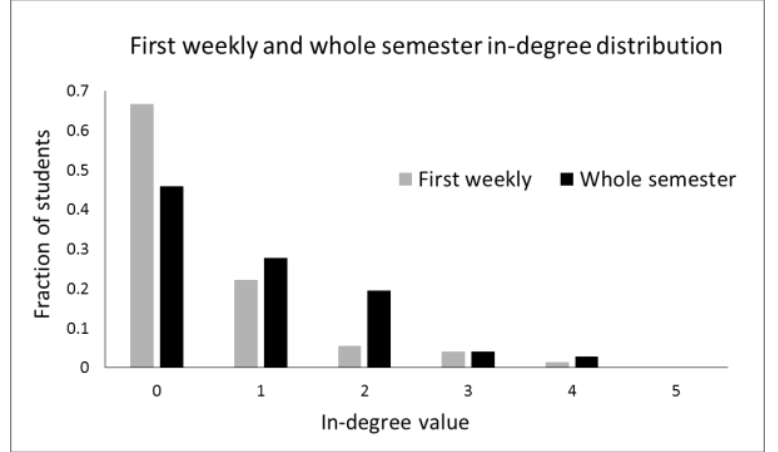

FIGURE 2B. First weekly and whole semester in-degree distribution of informal learning community in the lecture class.

Comparing the degree distributions of the two classes, it is clear that the ISLE class greatly fostered the formation of learning community outside of the classroom. We attribute this to the fact that the interactive components of the ISLE class, such as assembled class discussions and review sessions, introduced multiple channels for students to get to know each other and build relationships with each other. As the result of the limitations of the class size and classroom setup, interactive components of the lecture class were restricted to clicker question discussions and group quizzes. In an auditorium with a large capacity, interactions mainly happened between closest neighboring students who were usually from the same major program. The lack of interactions across the whole classroom resulted in weak bonding between students from different majors in the informal learning community outside the classroom.

\section{IMPACT OF PAGERANK CENTRALITY ON STUDENT SUCCESS}

The survey used in both classes provided students latitude to report the lists of people they worked with outside of the physics class. For the lecture class, 27 students reported tutor(s) in the learning center at CSUC as one of their study partners. Therefore, a "tutor" actor was introduced into the network of the lecture class so that the majority of students were connected within one network while 19 students in the class remained unconnected. The PageRank centrality was then calculated for each student in both classes.

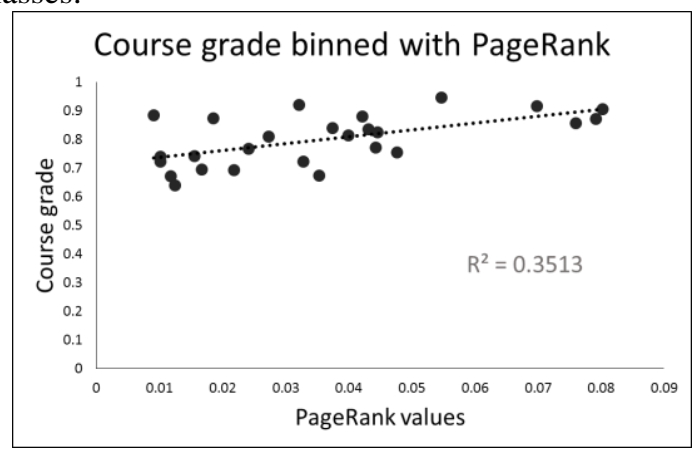

FIGURE 3A. Pearson correlation between students' course grades and PageRank of the ISLE class

In Figure 3A, the PageRank values of students in the ISLE class were correlated with their course grades using Pearson correlation and a $\mathrm{R}^{2}$ value of 0.35 was obtained. To account for the interrelatedness of PageRank values, in place of the standard parametric test of significance, we performed a Bootstrap t-test on this result with 100,000 times random sampling. A p-value of 0.0014 was obtained by this method. This result indicates that this correlation was significant. The correlation between students' course grades and their PageRank values showed that a student with high PageRank centrality in the self-organized learning community outside the classroom tended to do better in this course than those with low PageRank, possibly as the result of the fact that working with peers can motivate students to get their work done.

In contrast with the ISLE class data, nearly $1 / 3$ of the students in the lecture course received the same minimum PageRank value since they never reported anyone (including tutors) or been reported by any other classmates, while more than $1 / 3$ of students worked with only 1 partner (including tutors). Instead of examining correlation, with this data, we divided the students from the lecture class into 3 tertiles (24 students each) according to the ranking of their 
PageRank values. The average course grades of students in each tertile is shown in Figure 3B. The standard errors were labeled as error bars in the graph. The result shows that students within the top PageRank tertile did significantly better in the course than students in the other two tertiles. In comparing the difference in averages between tertile 2 and tertile 3 , a two-tailed bootstrap t-test with 100,000 times random sampling, yielded a p-value of 0.0020 .

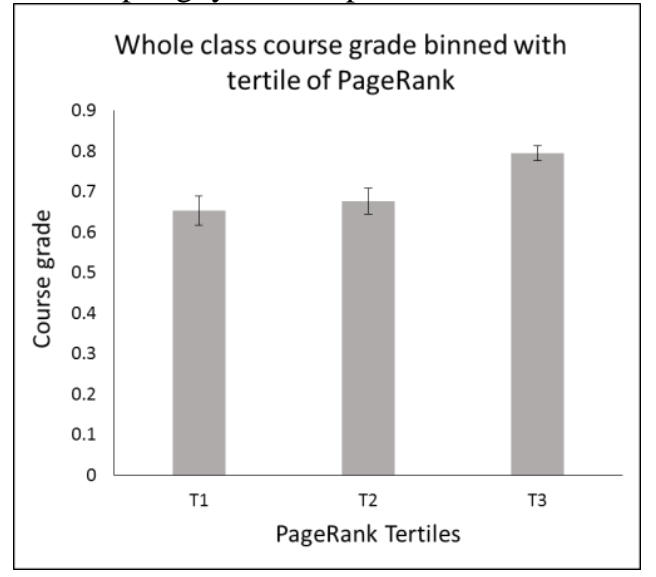

FIGURE 3B. Students' course grade binned with tertile of PageRank of the lecture class

\section{DISCUSSION AND CONCLUSION}

We used social network analysis to visualize and quantify each student's participation in the informal learning community that formed outside of two introductory physics classes. Comparisons between the two courses revealed that the class with interactive components helped students develop sense of learning community over the course of the semester, while the traditional lecture class, in the contrast, lacked that sense of learning community. The ISLE class data shows a correlation between PageRank centrality in the informal learning community and overall success in the course. It is just as likely that "stronger" students become central players in the network by virtue of others saying that they worked with them as much as those students are deriving a learning benefit by explaining physics ideas to their colleagues. The lecture class data is however, more interesting. What we observe is that students in the lecture class mainly choose to study with their friends or fellow majors. The isolating nature of the lecture hall means that "stronger" and "weaker" students have equal chance to be recognized as "go to" people who can provide help outside of class time. It is therefore plausible to argue that in the lecture class, it becomes more of each student's own choice to be part of the learning community or isolated from it. What we observe is that $\mathrm{T} 3$ in Figure 3B has a higher course grade by virtue of the absence of weak students rather than by the presence of exceptionally strong students. (Note the decreasing standard deviation from $\mathrm{T} 1$ to $\mathrm{T} 3$.) Therefore the lecture class data suggests the following claim: Being more central in the informal learning community is helping students, especially the "weaker" ones, to succeed in their physics courses.

\section{ACKNOWLEDGMENTS}

We would like to thank all members of PER Group at FIU for their feedback and encouragement. This research is supported by NSF grant \# 0802184 .

\section{REFERENCES}

1. L. Vygotsky, Mind in Society (Harvard University Press, Cambridge, MA, 1978), pp. 79-91

2. E. Brewe, L. Kramer, and V. Sawtelle, Phys. Rev. ST

Phys. Educ. Res. 8, 010101 (2012).

3. M. Bodin Phys. Rev. ST Phys. Educ. Res. 8, 010115 (2012).

4. I. Koponen and M. Pehkonen, Sci. Educ. 19, 259

(2010).

5. J. Forsman, Licentiate thesis, Uppsala University, 2011. 6. J. Forsman, C. Linder, R. Moll, D. Fraser, and S. Andersson, Stud. Higher Educ. 39, 68-86 (2012).

7. V. Pitts and J. Spillane, Int. J. Res. Meth. Educ. 32, $185-$ 207 (2009).

8. J. Pustejovsky and J. Spillane, Soc. Netw. 31, 221-229 (2009).

9. J. P. Spillane and C. M. Kim, Am. J. Educ. 119, 73-102 (2012).

10. A. Daly, Social Network Theory and Educational

Change, (Harvard Education Press, Cambridge, MA, 2010), pp. $115-126$

11. S. Dawson, J. Educ. Technol. Soc., 11, 224-238 (2008).

12. L. Macfadyen and S. Dawson, Comput. Educ. 54, 588599 (2010).

13. L. Lockyer, S. P. Dawson, L. Macfadyen, and D. Mazzochi-Jones, Australas. J. Educ. Tech. 27, 16-27 (2011).

14. E. Etkina and A. Van Heuvelen, "Investigative Science Learning Environment - A Science Process Approach to Learning Physics," in Research-Based Reform of University Physics, edited by E. F. Redish et al., American

Association of Physics Teachers, College Park, MD, 2007, Reviews in PER Vol. 1.

15. J. Bruun and E. Brewe, Phys. Rev. ST Phys. Educ. Res. 9, 020109 (2013).

16. E. Brewe, L. Kramer, and G. O’Brien, "Changing Participation Through Formation of Student Learning Communities" in Physics Education Research Conference -2010 , edited by M. Sabella et al. AIP Conf. Proceedings 1289, American Institute of Physics, Melville, NY, 2010, pp. 85-88. 